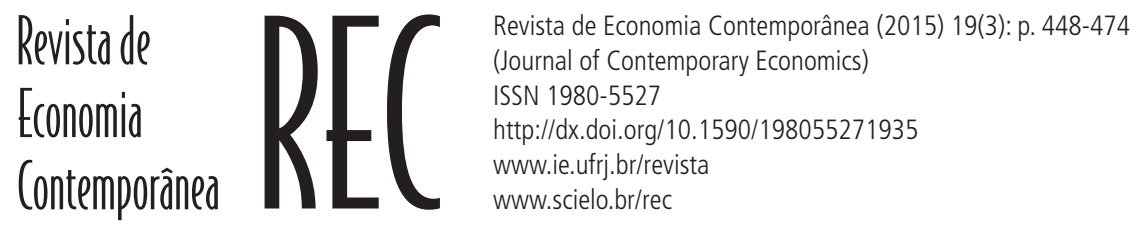

\title{
SUBDESENVOLVIMENTO E ESTAGNAÇÃO NA AMÉRICA LATINA, DE CELSO FURTADO
}

\author{
Mauricio C. Coutinho ${ }^{a}$

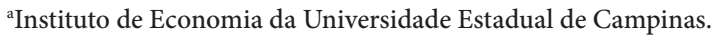

Artigo recebido em 20/08/2015 e aceito em 10/09/2015.

RESUMO: O artigo efetua uma apresentação do modelo estagnacionista de Celso Furtado (1965/1966), bem como da estrutura e argumentos gerais do livro Subdesenvolvimento e Estagnação na América Latina, de 1966. Propõe-se que o modelo estagnacionista de Furtado envolve uma reexposição de seu modelo clássico de desenvolvimento econômico do Brasil, a qual envolve a utilização do acelerador. Se as conclusões estagnacionistas são controversas no que se refere aos impasses da diversificação da estrutura industrial latino-americana e brasileira nos anos 1960, a apresentação do modelo representa um acréscimo ao modelo histórico-estrutural de Furtado e contribui para o entendimento dos recursos analíticos do autor. O livro de 1966 contém ainda valiosas contribuições sobre política brasileira, consequências da penetração do capital industrial internacional e impactos sobre a distribuição de renda.

PALAVRAS-CHAVE: estagnação; Celso Furtado; desenvolvimento latino-americano.

CLASSIFICAÇÃO JEL: B29. 


\title{
UNDERDEVELOPMENT AND STAGNATION IN LATIN AMERICA, BY CELSO FURTADO
}

\begin{abstract}
The paper aims at presenting the core of Celso Furtado's 'stagnation model' (1965/1966), as well as the structure and general content of his 1966 book Underdevelopment and Stagnation in Latin America. It is argued that Furtado's stagnation model implies a redefinition of his classical account of the Brazilian economic development, involving the utilization of the accelerator. Although the stagnation hypothesis is controversial, at least in what refers to the inevitability of a decrease in the rate of growth sequent to industrial diversification, the development of the model adds to the understanding of Furtado's historical-structural method, and contributes to the assessment of the author's analytical resources. The 1966 book involves additional contributions, as those referred to Brazilian politics, impacts of the multinational enterprises, income distribution.
\end{abstract}

KEYWORDS: stagnation; Celso Furtado; Latin American development. 


\section{INTRODUÇÃO}

Apesar da notoriedade do autor, Subdesenvolvimento e Estagnação na América Latina, de Celso Furtado (1966a) teve o destino peculiar de permanecer na memória e no debate econômico brasileiros mais pela crítica de ampla repercussão de Tavares e Serra (1971) do que por seu conteúdo específico ${ }^{1}$. Essa inversão de perspectivas deve-se, possivelmente, ao fato de o crescimento acelerado da economia brasileira a partir de 1967 ter tornado fácil submergir a contribuição de Furtado no caudal indistinto dos prognósticos estagnacionistas do início dos anos 1960. A propósito, Tavares e Serra (1971)apresentam Furtado como o proponente mais aberto da "crença da estagnação" (sic), prejudicial ao entendimento das economias da região ${ }^{2}$.

Desse modo, circunstâncias e controvérsias de momento, para não falar em certo anacronismo dos críticos, contribuíram para que o livro de 1966 perdesse a identidade e deixasse de ingressar na história do pensamento econômico brasileiro como o que de fato é: uma das principais obras de Celso Furtado. Acredito que uma leitura afastada do calor dos debates permite concluir que os ensaios abrigados em Subdesenvolvimento e Estagnação ultrapassam a defesa do estagnacionismo, chegando a representar uma meditada revisão e reexposição do modelo básico de análise histórico-estrutural na visão de seu principal formulador. Essa revisão envolve acréscimos ao entendimento da economia agrário-exportadora, do processo de substituição de importações, do significado da passagem do período primário-exportador ao de industrialização, da dualidade estrutural, enfim, de temas nucleares da agenda de investigações de Furtado.

A obra tem méritos adicionais. Por um lado, avança na integração entre estrutura de produção e distribuição de renda, um dos aspectos do estruturalismo e das contribuições do autor que está por merecer atenção mais detida. Por outro, ilustra uma faceta que apenas agora começa a receber atenção dos biógrafos e comentadores, a do Furtado analista político ${ }^{3}$. Em poucas ocasiões - talvez apenas nos volumes de memórias, de datas bem posteriores - o bisturi frio do analista político cortou com tamanha

1 Subdesenvolvimento e Estagnação na América Latina (Furtado, 1966a) abrange diversos ensaios. O capítulo três, que desenvolve o núcleo do modelo estagnacionista, é a versão em português de Furtado (1965b), Furtado (1966b) e Furtado (1966c). A obra de Furtado e Maneschi (1968) contem uma variação do modelo estagnacionista.

2 O presente artigo não efetua uma análise específica da crítica de Tavares e Serra a Furtado, que será objeto de outro estudo. Exposição e crítica semelhantes ao modelo de estagnação de Furtado encontram-se em Rodriguez (2009).

3 Sobre o Furtado analista político discorrem Boianovsky (2014), Cepêda (2001), Bianconi (2015) e Oliveira (1983). 
precisão ${ }^{4}$. Finalmente, Subdesenvolvimento e Estagnação introduz um elemento novo e crucial na análise de Furtado: a moderna empresa internacional e seus impactos sobre a economia latino-americana ${ }^{5}$. Como se vê, sobram razões para que uma obra tão representativa seja reavaliada, em especial se o objetivo for, como é o caso no presente artigo, o de revisar as características e a evolução do pensamento de Furtado ${ }^{6}$.

O fio condutor da exposição é a emergência ea plena utilização da relação produto/capital no esquema analítico de Furtado. Essa é uma característica crucial de Subdesenvolvimento e Estagnação, e pretende-se argumentar que ela acresce à descrição do período primário-exportador e, em especial, à clássica representação da economia cafeeira de Furtado $(1959)^{7}$. Contribui ainda para o entendimento da recuperação diante da crise de 1929 e da transição ao processo de substituição de importações. Em que medida a relação produto/capital acresce ao entendimento da complementação da estrutura industrial e a um corolário seu, que é a tese estagnacionista, é um tema para debates. Em suma, e conforme se vai expor, a tese estagnacionista é um corolário da visão de Furtado (1966a) sobre as vicissitudes da diversificação e complementação da estrutura industrial na América Latina; um corolário às vezes problemático, porém, crucial para entendermos a natureza da narrativa e dos recursos analíticos do autor.

Além desta Introdução, o presente artigo desdobra-se em quatro seções. A seção dois procura oferecer uma visão de conjunto (necessariamente sintética) dos ensaios abrigados em Subdesenvolvimento e Estagnação na América Latina. A seguinte apresenta o argumento estagnacionista, tal como desenvolvido no capítulo 3 do livro de Furtado (1966a), revisando os usos da relação produto/capital nesta versão do modelo de reconstrução racional da história. A quarta seção rastreia a relação produto/capital na obra de Furtado, identificando duas origens: os exercícios de programação da CEPAL, dos anos 1950, e a releitura e reexposição dos modelos pós-keynesianos de crescimento, característica de Teoria e Política do Desenvolvimento Econômico (Furtado, 1967). A quinta seção apresenta as conclusões.

4 Os volumes de memórias são Furtado (1985), Furtado (1989) e Furtado (1991).

5 A introdução da empresa internacional no quadro de análise representa uma contribuição da etapa "norte-americana" do exílio de Furtado, vale dizer, do período que o autor passou nos Estados Unidos, antes de se transferir em definitivo para a França. Bianconi (2015) esclarece que em 1964, em Santiago, Furtado havia participado no ILPES de seminários sobre empresas multinacionais e internacionalização da economia latino-americana.

6 O diagnóstico estagnacionista de Furtado foi objeto de comentários em Salm (2011) e Bugelli e Pires (2011). Acredito que o presente artigo não duplica, ou se sobrepõe, a esses comentários.

7 Formação Econômica do Brasil (Furtado, 1959) teve diversas edições com texto inalterado. No presente trabalho nos valemos da edição comemorativa do cinquentenário de publicação (Furtado, 2009). 


\section{SUBDESENVOLVIMENTO E ESTAGNAÇÃO NA AMÉRICA LATINA- O PLANO GERAL}

Conforme mencionado, Subdesenvolvimento e Estagnação é uma das obras em que Furtado mais se aplica à análise política do desenvolvimento latino-americano, assim como ao exame da particular situação política brasileira do início dos anos 1960. A bem da verdade, dos cinco capítulos que compõem o livro, três poderiam ser considerados predominantemente políticos, se for razoável estabelecer uma distinção tão nítida entre política e economia na obra de Furtado. Apenas um capítulo - o terceiro, no qual o modelo estagnacionista é apresentado - pode ser considerado essencialmente econômico, no sentido de ser voltado à apresentação de um modelo de explicação da realidade com dominância de variáveis econômicas.

No primeiro capítulo, "Em busca de uma ideologia do desenvolvimento", Furtado (1966a) parte do contraste básico entre a industrialização que resulta da Revolução Industrial e aquela que decorre do processo de substituição de importações para passar de imediato à avaliação das consequências políticas de um e de outro processo. De acordo com sua argumentação, enquanto nos países que viveram a Revolução Industrial clássica a dinâmica entre progresso tecnológico e crescimento dos salários reais permitiu que a luta de classes viesse a desembocar em um quadro no qual a racionalidade empresarial acabou por se conciliar com os interesses da coletividade, na América Latina tal conciliação não ocorreu. A industrialização se sobrepôs a um mercado de trabalho desestruturado, ou a uma situação caracterizada pela existência de um amplo contingente populacional em situação de subsistência. O dualismo estrutural não foi eliminado, já que a indústria incorpora funções de produção poupadoras de mão de obra, definidas em países em que o nível de salário real é mais elevado. O dualismo estabelece de imediato um contraste entre a racionalidade empresarial e a possibilidade de elevação do nível de vida das massas, um fenômeno de amplas consequências políticas.

Para Furtado, o processo de industrialização latino-americano não criou o proletariado clássico. As cidades são habitadas por uma "massa urbana de estrutura pouco definida" (Furtado, 1966a, p. 12), cuja pressão para ter acesso aos frutos do desenvolvimento não deve ser confundida com a luta de classes padrão. Enquanto nos países europeus a luta de classes encontrou uma solução no campo da técnica, por meio da dinâmica entre aumento de produtividade e crescimento dos salários reais, as aspirações das massas latino-americanas desembocaram diretamente em um ambiente político incapaz de atendê-las. O resultado é a emergência de uma instabilidade social que desemboca em soluções políticas variadas, que oscilam do populismo ao autoritarismo.

Furtado (1966a) critica agudamente tanto as políticas populistas quanto as alternativas que enfatizam a luta de classes. Hostiliza ainda as soluções autoritárias, as quais, a despeito de pretenderem eliminar a agitação social, não obtêm sucesso, exata- 
mente porque a insatisfação social resulta da exclusão. Na visão do autor, a única alternativa positiva teria sido uma política:

(...) visando à consecução do crescimento econômico e da modernização social, mediante modificações no processo de organização de produção que tornem possível racionalizar a assimilação de novas técnicas em função do interesse social. (Furtado, 1966a, p. 15)

Como se sabe, o planejamento é o cerne dessa política. Embora no capítulo 5 ("Aspectos operacionais da política de desenvolvimento") sejam expostas as bases técnicas de tal política, ao longo dos outros capítulos encontram-se repetidas referências à necessidade (e às dificuldades) de organizar massas heterogêneas em torno de um projeto nacional de tamanha complexidade. Ao leitor fica a impressão de que, mesmo para Furtado, o planejamento representa uma estratégia necessária e racional de dificílimo alcance.

De fato, a despeito de não perder de vista a possibilidade de superação virtuosa da crise política e das dificuldades econômicas trazidas pelo esgotamento do processo de substituição de importações, o tom de Subdesenvolvimento e Estagnação é marcadamente pessimista. Furtado vê os impasses políticos latino-americanos como a contraface de um processo de desenvolvimento que não conseguiu cumprir a tarefa histórica de eliminar a economia de subsistência, ou seja, esvaziar as ocupações com baixíssimos níveis de produtividade. Isso significa que a industrialização latino-americana convive com a concentração de renda. Além disso, o processo substitutivo provoca permanentes desajustes entre as estruturas de oferta e de demanda, os quais, por sua vez, alimentam as pressões inflacionárias e a tendência à erupção de crises cambiais.

Conforme expõe Furtado (1966a), ao final da década de 1950 era já perceptível que o processo de substituição de importações extinguira seu virtuosismo. O crescimento econômico e a urbanização a ele associados, se inicialmente possibilitaram o atendimento às aspirações das massas mesmo em presença de estruturas políticas arcaicas, levaram, por fim, a um impasse político e econômico. A crise política do início dos anos 1960 se revelaria estrutural, exatamente por decorrer de um impasse econômico inerente ao modelo substitutivo. O capítulo 2, "Obstáculos externos ao desenvolvimento", ao adicionar uma dimensão internacional à análise, apenas corrobora seu teor pessimista ${ }^{8}$. Ao examinar os dilemas da Guerra Fria e do equilíbrio de super-

8 Esse capítulo foi publicado no Jornal do Brasil na edição de 06/03/1966 com o título de "A hegemonia dos Estados Unidos e o futuro da América Latina”. Veio a ser publicado também na World Today, em 
potências consolidado no pós-guerra, Furtado (1966a) conclui que a política de contenção do comunismo seguida pelos Estados Unidos contribuiu para minar as possibilidades de uma evolução política positiva na América Latina - ponto também percebido por Hirschman ${ }^{9}$. Se na cartilha da Guerra Fria a insatisfação das massas é vista como algo estimulado pelo movimento comunista, após a crise dos mísseis em Cuba o quadro se agravou ${ }^{10}$. Por sua vez, a resposta conservadora às demandas populares, por ser imobilista, não é capaz de conter essa insatisfação. O desenvolvimento, uma espécie de terceira via com o potencial de promover a modernização e a democracia, colidia com os interesses conservadores e esbarrava na desconfiança dos próprios norte-americanos.

Não bastassem tais obstáculos, Furtado (1966a) acrescenta um novo e grandioso tópico: a incompatibilidade entre a grande empresa moderna, a democracia e a soberania dos Estados. Se nos Estados Unidos a convivência entre as megacorporações e a representação popular já é traumática, o que dizer da América Latina, onde as corporações são, além de tudo, estrangeiras? Furtado é explícito:

O primeiro problema que se coloca, do ponto de vista da América Latina, é o de indagar que tipo de organização política poderá ser compatível, nos países latinoamericanos, com um sistema econômico regional principalmente controlado por poderosas sociedades anônimas norte-americanas. (Furtado, 1966a, p. 43)

Furtado incorpora as opiniões sobre a tecnocracia moderna de autores como Berle e Hacker ${ }^{11}$, que entendem serem as grandes corporações organizações dirigidas por poderosas burocracias privadas que exercem funções públicas ou semipúblicas. A conciliação entre essas burocracias e uma sociedade política pluralista é sempre difícil. Para agravar o quadro, o primado das grandes corporações internacionais acentua a tendência das classes dirigentes latino-americanas a considerarem obsoleto o nacionalismo. Os projetos nacionais, inclusive o planejamento, convertem-se em aspiração exclusiva da parcela da população com menor poder decisório. Para finalizar, a grande empresa utiliza tecnologias pouco empregadoras, o que não representa uma resposta positiva ao grande dilema do dualismo estrutural.

setembro de 1966 e, sem as conclusões, na Esprit de julho de 1966.

9 A respeito, ver Adelman (2013).

10 Artigos de Kennan e Morgenthau são mencionados nas reflexões de Furtado sobre a Guerra Fria.

${ }^{11}$ Furtado (1966) se refere a textos de Berle e Hacker publicados em 1964, em uma obra organizada por Hacker, Corporate America. 
Em suma, ao incorporar ao panorama político as restrições trazidas pelo quadro internacional, Furtado (1966a) estreita o horizonte em que se podem exercer políticas de desenvolvimento integradoras da massa da população. O clima de tensão entre as superpotências, bem como a internacionalização do capital produtivo, teriam restringido dramaticamente as soluções políticas, bem como agravado a incompatibilidade básica entre os métodos de produção e a dotação de fatores das economias latino-americanas. O capítulo 4, "Análise do caso do Brasil", não representa uma mera aplicação do modelo estagnacionista (apresentado no capítulo terceiro da obra; a ser revisado na próxima seção deste trabalho). Nele, Furtado retoma as características do processo de industrialização brasileiro, examina as condições políticas em que se deu este processo para, afinal, lançar-se a uma crítica impiedosa dos mecanismos de representação que asseguram a manutenção do atraso político. Nessa medida, o capítulo complementa a perspectiva política dos dois primeiros capítulos, com o acréscimo de, ao se referir a um quadro nacional específico, permitir uma precisão que escapa aos modelos gerais aplicáveis à América Latina ${ }^{12}$. Furtado (1966a) detém-se especificamente nos critérios de representação do Congresso brasileiro, os quais, ao falsearem a representação popular em favor do controle oligárquico, intensificaram os conflitos entre legislativo e executivo tão característicos da cena política do pós-guerra.

Para Furtado, a característica mais expressiva do processo histórico brasileiro nos últimos dois decênios teria sido "a emergência de uma sociedade de massas abrindo caminho ao populismo, sem que se hajam formado novos grupos dirigentes capacitados para estruturar um projeto de desenvolvimento nacional em contraposição à ideologia tradicionalista" (Furtado, 1966a, p. 106). A intervenção militar de 1964 teria sido fruto desse impasse político. Resultou, portanto, de uma crise de representação, a qual, vale lembrar, tem a peculiaridade de estar, em última análise, relacionada ao modelo econômico concentrador. Em suma, foram as características da industrialização substitutiva que impediram a integração da massa de trabalhadores à polis e ao mercado consumidor, em um processo em tudo contrário ao que ocorreu no modelo de industrialização clássico. O autoritarismo e a negação da democracia pluralista nada mais representariam do que uma consequência funesta da combinação da "penetração da técnica moderna" e da ausência, no seio das classes dirigentes, de pessoas "apto(a)s para liderar a reforma das estruturas sociais" (Furtado, 1966a, p. 107).

\footnotetext{
12 Esse capítulo havia sido apresentado em um seminário realizado em Londres e publicado sob o título "Political obstacles to economic growth in Brazil" (Furtado, 1965a). O mesmo texto foi publicado na revista Civilização Brasileira em março de 1965.
} 


\section{O MODELO DE ESTAGNAÇÃO DE FURTADO}

O núcleo do modelo de estagnação é apresentado no capítulo três, "Fatores estruturais internos que impedem o desenvolvimento" ${ }^{\text {"13 }}$. Vale observar que, embora o modelo tivesse a finalidade de explicar fenômenos correntes, como a inflação e a redução da taxa de crescimento ocorridas nos anos 1960, remete - no que é típico do método histórico-estrutural - aos "fatores estruturais" associados à industrialização latino-americana. A industrialização por substituição de importações, por sua vez, requer o entendimento do surto primário-exportador que a antecedeu. É por essa razão que o capítulo contém, na realidade, dois modelos: o que se refere ao período primário-exportador e o que se refere ao processo de substituição de importações. Do contraste entre os dois, Furtado tira suas conclusões.

Os dois modelos representam uma aplicação do método de racionalização da história com base em variáveis e categorias econômicas, peculiar a Furtado. Aliás, é curioso constatar que é nesta obra dedicada à crise da industrialização que se encontra uma das melhores explicações da dinâmica da economia primário-exportadora. Aspectos da dinâmica cíclica na agricultura que permaneceram obscuros mesmo em exposições clássicas do desenvolvimento econômico brasileiro, como a de Furtado (1959), tornam-se mais claros. O modelo agrícola de Subdesenvolvimento e Estagnação joga luz, no mínimo, sobre os seguintes (e complexos) temas: relação entre agricultura de exportação e agricultura de subsistência; dinâmica do excedente na agricultura; o processo de concentração de renda na economia agroexportadora; a dinâmica de absorção de mão de obra na agricultura; a natureza do investimento no setor exportador; o paradoxo da combinação de oferta ilimitada de terra e exclusão de acesso à terra da massa da população; a estrutura política da sociedade agroexportadora. São temas aos quais não se poderá dar o devido destaque nesta exposição, mas que se encontram bem desenvolvidos em Subdesenvolvimento e Estagnação.

Pelo fato de a exposição do modelo de crescimento da economia agroexportadora ser um dos pontos altos da obra, e por Furtado (1966a) valer-se do contraste entre a dinâmica do crescimento agroexportador e a da industrialização para caracterizar os limites e impasses dessa última, é importante nos alongarmos no modelo agrícola.

\footnotetext{
13 O capítulo 3 é a versão em português de trabalhos publicados anteriormente. Ver nota 1.
} 


\subsection{O MODELO AGROEXPORTADOR}

O modelo agrícola de Subdesenvolvimento e Estagnação envolve três variações em relação a versões anteriores do processo de desenvolvimento "para fora". Em primeiro lugar, o setor agrícola é desdobrado em três - e não mais apenas em dois - setores (exportador e de subsistência). Na presenteversão, $\mathrm{P}_{1}, \mathrm{P}_{2}$ e $\mathrm{P}_{3}$ correspondem respectivamente a setor de subsistência, setor exportador e setor provedor de capacidade produtiva para o setor exportador. Como veremos, a subdivisão da agricultura de exportação em $\mathrm{P}_{2} \mathrm{e}$ $\mathrm{P}_{3}$ favorece a compreensão da dinâmica do emprego, das relações intersetoriais na agricultura e da formação da poupança, um ponto-chave no sistema de Furtado.

A segunda inovação, presente tanto no modelo agrícola quanto no modelo de industrialização, é a explicitação da relação produto/capital. Nesse aspecto - e conforme será desenvolvido na próxima seção -, Furtado (1966a) nada mais fez do que transpor para o interior de modelos de crescimento multissetoriais uma variável central dos modelos de crescimento econômico dos anos 1940 e 1950, presente nos exercícios de planejamento da CEPAL dos anos 1950.

A terceira inovação, em parte facilitada pelo desdobramento do setor exportador em $\mathrm{P}_{2}$ e $\mathrm{P}_{3}$, refere-se à análise do processo de formação de capital e da adequação entre poupança e investimento. Ao longo de sua obra, Furtado mostrara-se preocupado com a formação da poupança necessária ao investimento requerido para se manter determinada taxa de crescimento. Nesse particular, o modelo distingue a expansão de capital que requer poupança prévia da que não requer: se o capital requerido pela atividade exportadora é muito alto, apenas uma pequena parte (aquisição de equipamentos, alguma infraestrutura) requer poupança prévia. No fundamental, a expansão do cultivo envolve apenas trabalho acumulado, mantido com a produção agrícola obtida na própria terra. Essa "formação interna de capital” típica da agricultura, potenciadora da capacidade de autoexpansão dos investimentos, fora assinalada por Furtado em obras anteriores. A novidade é apresentá-la como denotadora de uma relação produto/capital dupla: baixa, se levarmos em conta o capital total; elevadíssima, se levarmos em conta apenas o capital que demanda poupança anterior. A relação produto/capital dupla é essencial à dinâmica do modelo agroexportador de Furtado. Vejamos o núcleo do modelo agrícola exportador de Subdesenvolvimento e Estagnação. Na visão de Furtado (1966a), a expansão do setor exportador inicia-se sempre com a integração da agricultura a um fluxo dinâmico do comércio internacional, que mobiliza os recursos ociosos na agricultura - terra e capital - e provoca um aumento na produtividade global da economia, pela simples transferência de mão de obra de um setor de baixíssima produtividade (o de subsistência) a outro de produtividade mais elevada. No modelo trissetorial, a expansão da capacidade produtiva de $\mathrm{P}_{2}$ pressupõe o aumento das atividades em $\mathrm{P}_{3}$. 
Essa expansão de $\mathrm{P}_{2}$ e $\mathrm{P}_{3}$ é efetuada com o influxo de mão de obra do setor de subsistência, ou seja, envolve migração de trabalhadores de uma situação de baixa produtividade a uma de alta produtividade, o que acarreta elevação da produtividade global.

Economias com excedente de mão de obra têm a possibilidade de se desenvolver com a mera transferência de população de setores nos quais a mão de obra é redundante - portanto, o produto marginal do trabalho é zero - para aqueles que conseguem empregar com maior eficiência a população migrada. Isso vale tanto para o processo de industrialização, conforme a abordagem clássica da teoria do desenvolvimento, quanto para fases de crescimento baseadas na expansão de atividades agrícolas dinâmicas ${ }^{14}$.

O problema é a formação de capital (e a poupança prévia) nas atividades dinâmicas. Para Furtado (1966a), a característica da formação de capital na agricultura de exportação é a baixa exigência de poupança prévia, na medida em que a própria mão de obra incorporada provê sua subsistência, plantando em terras momentaneamente disponíveis e/ou nas entrelinhas de cultivos permanentes. Em suma, temos aqui um conceito mais amplo de investimento, conforme o qual "a própria expansão da agricultura cria os recursos que alimentam o processo de investimento" (Furtado, 1966a, p. 67).

A subdivisão da agricultura de exportação em dois subsetores $-\mathrm{P}_{2}$ e $\mathrm{P}_{3}$ - facilita o entendimento desse processo, uma vez que $\mathrm{P}_{3}$ é o setor de investimento na produção de bens exportáveis (produzidos em $\mathrm{P}_{2}$ ). Ora, na medida em que a expansão de $\mathrm{P}_{3}$ requer um baixo nível de poupança prévia, passamos a ter uma relação produto/capital dupla: razoavelmente baixa - Furtado estima 0,4 -, se considerarmos o capital total; alta - Furtado admite 4, já que o investimento dependente de poupança prévia corresponde a não mais de $10 \%$ do total -, considerando-se o capital que requer recursos prévios. Portanto, a mera expansão da demanda de produtos de exportação eleva a eficiência do capital. $\mathrm{P}_{3}$ vem atuar como um "setor produtor de equipamentos, [...] submetido a um mecanismo de aceleração toda vez que se expande a demanda dos bens produzidos com os referidos equipamentos" (Furtado, 1966a, p. 67).

Admitindo-se que a produtividade da mão de obra e a taxa salarial sejam as mesmas em $\mathrm{P}_{2}$ e $\mathrm{P}_{3}$, o excedente e a taxa de lucro também serão. Como a expansão da atividade exportadora implica um aumento da participação relativa de $\mathrm{P}_{3}$ na agricultura, verifica-se um aumento da taxa de investimento global - o produto de $\mathrm{P}_{3}$ confunde-se com o investimento - e, conforme mencionado, uma elevação simultânea da relação produto/capital. Esses dois fatores provocam a elevação da taxa de crescimento da economia, que é dada, nos termos da condição de equilíbrio dinâmico de Harrod e de

\footnotetext{
${ }^{14}$ Sobre transferência de mão de obra e implicações sobre a produtividade global nos modelos clássicos de desenvolvimento com excedente de mão de obra ver Nurkse (1953), Lewis (1953), Furtado (1954).
} 
Domar, pelo produto da taxa de investimento (propensão a poupar, para Furtado) pela relação produto/capital.

Para Furtado (1966a), a questão é se a economia consegue gerar a poupança compatível com o investimento efetuado. Sua conclusão é peculiar: no modelo agroexportador, a própria expansão da atividade exportadora assegura a poupança necessária, uma vez que a produção de $\mathrm{P}_{3}$ (que acompanha a expansão de $\mathrm{P}_{2}$ ), não podendo ser consumida ou exportada, tem como destino obrigatório a incorporação à capacidade produtiva. Ou seja, do ponto de vista da composição de demanda, o investimento é garantido.

Temos aqui um círculo virtuoso, no qual aumentam ao mesmo tempo a produtividade do capital e a taxa de poupança. Se preferirmos, pode-se falar em convergência entre o nível de demanda e uma composição da demanda que assegura um ritmo elevado de crescimento. Nos termos de Furtado:

Como $\mathrm{P}_{2}$ e $\mathrm{P}_{3}$ devem ser considerados conjuntamente, como dois subsetores da agricultura capitalista que se interpenetram, deduz-se que a relação produto/capital tenderá a ser tanto maior nessa agricultura quanto mais elevada for sua taxa de crescimento. Por outro lado, sempre que façamos investimento e poupança iguais expost,... o aumento da participação de $\mathrm{P}_{3}$ na produção total implica a elevação na taxa de poupança, pois ao crescer $\mathrm{P}_{3}$ a produção de $\mathrm{k}$ [capital produzido sem recursos prévios] aumenta necessariamente com a mesma intensidade. Como $\mathrm{k}$ não pode ser consumido ou exportado, devendo necessariamente incorporar-se à capacidade produtiva, infere-se que seu crescimento relativo significa, ceteris paribus, um aumento da taxa de poupança, ex post. (Furtado, 1966a, p. 67-68)

Vale lembrar que Furtado (1966a) considera que a produtividade do trabalho nos dois setores vinculados à exportação situa-se em um nível superior ao do setor de subsistência, enquanto os salários são limitados pelo excedente de mão de obra em $\mathrm{P}_{1}$. Em decorrência, há uma menor apropriação da renda do setor pelos trabalhadores. A virtude do modelo agroexportador é que parte dos lucros fica necessariamente represada para acumulação, sem poder ser consumida pelas classes proprietárias A compatibilização entre oferta e demanda gera um mecanismo retroalimentador, uma vez que a manutenção da taxa de crescimento requer poupança em níveis elevados, algo automaticamente assegurado pela própria composição da demanda.

Um aspecto interessante do modelo agrícola multissetorial é a conclusão de que o aumento da concentração de renda não impede o crescimento econômico, uma vez que a composição da demanda necessariamente envolve investimentos (o setor $\mathrm{P}_{3}$ ). $\mathrm{O}$ vazamento da renda para o consumo supérfluo, ou para a importação de bens de con- 
sumo, é limitado pela própria natureza da atividade econômica. Pode-se concluir que, a despeito de o modelo ser exportador, em condições de expansão da atividade exportadora o ajustamento entre as estruturas de oferta e de demanda produz crescimento e aumento do bem-estar; vale dizer, mais população é incorporada à agricultura dinâmica, com salários ligeiramente superiores aos rendimentos obtidos no setor de subsistência. Além disso, como inexistem barreiras à expansão da oferta, mesmo um crescimento acelerado não gera pressões inflacionárias.

O círculo virtuoso é interrompido quando a taxa de crescimento das exportações declina. Nessas condições, enquanto houver transferência de mão de obra do setor de subsistência para os demais, crescerão a produtividade do trabalho e a remuneração do trabalhador. Em certo ponto, no entanto, reduz-se $\mathrm{P}_{3}$ (e diminui-se a transferência de mão de obra do setor de subsistência); persistindo o declínio do crescimento das exportações, o desemprego em $\mathrm{P}_{3}$ será superior à absorção de mão de obra em $\mathrm{P}_{2}$, o que implica retorno da população a $\mathrm{P}_{1}$. Por outro lado, o decréscimo da produção em $\mathrm{P}_{3}$ indica contração da poupança. Ocorrerá, portanto, um decréscimo da produtividade do trabalho, da taxa de poupança e da taxa de crescimento global. Um hipotético movimento compensatório - recomposição do excedente por meio de compressão salarial - teria limites estreitos, uma vez que o salário nos setores dinâmicos é fixado em nível próximo ao de subsistência. Em condições normais, a cessação do crescimento da atividade exportadora - causada por abarrotamento dos mercados, queda de preços etc. - gera um refluxo em direção às atividades de subsistência, queda de produtividade do sistema e queda do investimento.

\subsection{A INDUSTRIALIZAÇÃO POR SUBSTITUIÇÃO DE IMPORTAÇÕES}

A passagem a um regime de industrialização por substituição de importações é feita sob o impacto de uma crise do comércio internacional sem precedentes. A abordagem clássica de Furtado, retomada em Subdesenvolvimento e Estagnação, considera que, sob certas condições - preexistência de um mercado interno de tamanho considerável, manejo conveniente das restrições cambiais -, a crise do setor exportador pode dar origem a um processo de modificação na estrutura produtiva mediante a expansão das atividades industriais. Isso evita que a redução da participação das importações na oferta interna leve a uma regressão à economia pré-capitalista. Trata-se, então, de analisar se a economia pode crescer a altas taxas e de modo persistente no novo regime; em outras palavras, se o processo de modificação da estrutura produtiva feito sob restrições externas não leva necessariamente a um impasse, em particular quando se trata de produzir internamente os itens "de substituição mais difícil”. 
A rigor, a argumentação desdobra-se em duas partes. Em um primeiro momento, cabe mostrar que a indústria de bens de consumo não duráveis pode vir a substituir a agricultura de exportação como setor dinâmico da economia. Posteriormente, com a evolução do processo de substituição de importações, acompanhar as possibilidades e consequências da complementação da malha industrial pela implantação de indústrias de bens de consumo duráveis e de equipamentos. Para Furtado (1966a), o desenvolvimento da produção local de bens de consumo não duráveis industriais, ou a substituição da agricultura pela indústria como setor dinâmico, decorreu do encarecimento relativo dos bens importados, provocado pela desvalorização das moedas locais e pela imposição de barreiras tarifárias em um quadro em que o crédito à formação de estoques de produtos agrícolas exportáveis preservou a renda interna. Em suma, a modificação da demanda agregada, em virtude das restrições externas, impulsionou um processo de transformação na oferta agregada.

É de notar que a modificação da taxa de câmbio e as barreiras tarifárias impulsionaram a produção industrial local, em especial a dos bens de consumo correntes, cuja elaboração requer restrições tecnológicas menos severas. De acordo com Furtado (1966a), a mudança na estrutura de custos, em conjunto com pressões dos diversos grupos sociais em favor de suas rendas ou produtos, modifica os preços relativos e altera a distribuição de rendimentos - o que atua na compatibilização entre estruturas de oferta e de demanda. O resultado final é a subida dos preços dos bens finais da indústria (como reflexo dos preços dos bens importados), o que, em condições de salário real estável, impulsionou a taxa de lucro do setor.

Curiosamente, para ilustrar os impactos dessa restrição externa súbita sobre a relação produto/capital, Furtado (1966a) introduz um exemplo hipotético que não leva em consideração as mudanças na taxa de câmbio. Em termos resumidos, o exemplo utiliza salários e uma relação capital por trabalhador denominados em dólares, simulando as mudanças nos lucros individuais provocadas pela ocupação maior da capacidade instalada (por multiplicação de turnos, por exemplo) ${ }^{15}$. Enfim, paradoxalmente, analisa-se um aumento da produtividade do capital por maior utilização da capacidade instalada, na ausência de modificações de preços relativos - ou, ao menos, daquelas modificações provocadas pela referida desvalorização cambial.

O resultado é um aumento da taxa de lucro e da relação produto/capital da indústria, o que, de certo modo, atenua os impactos negativos sobre o crescimento econômico provocados pela queda da relação produto/capital global. Convém lembrar que a

\footnotetext{
${ }^{15}$ O exemplo é apresentado na página 74 de Furtado (1966a).
} 
queda da relação produto/capital global é uma consequência inevitável da perda de primazia do setor agrário exportador, cujas características virtuosas foram vistas.

Ao analisar a transferência dos capitais para a indústria, em condições de contração brusca do subsetor $\mathrm{P}_{3}$, Furtado (1966a) mergulha nas dinâmicas das produtividades do trabalho e do capital, bem como das taxas de lucro. A questão passa a ser: o que assegura que os capitalistas dirijam seus investimentos ao setor industrial, especificamente, ao setor de produção de bens de consumo corrente $\left(\mathrm{P}_{4}\right)$ ? Por que razão seus recursos não são dirigidos a outros ativos igualmente promissores - pensemos nas oportunidades de ganhos imobiliários proporcionados pela expansão urbana - ou não aumenta o consumo de luxo? Na visão de Furtado (1966a), a chave para que os recursos sejam mantidos ou dirigidos ao setor industrial é a maior produtividade do trabalho na indústria. Em condições de salários reais contidos pelo setor de subsistência, a elevada produtividade do trabalho na indústria condiciona uma taxa de lucro bruto superior à agrícola. A elevação da taxa de lucro, bem como da concentração de renda, impulsionam a taxa de poupança, proporcionando um contraponto à redução da eficiência do capital inerente à perda de liderança da agricultura exportadora.

O crescimento econômico é mantido graças a uma espécie de trade-off, pelo qual a perda das virtudes dinâmicas da agricultura de exportação é, de certo modo, compensada por dois movimentos: em um momento inicial, pela utilização de capacidade instalada e decorrente elevação da relação produto/capital marginal e média da indústria, sem novos investimentos; e posteriormente por uma margem sobre os custos salariais capaz de compensar, via taxa de lucro, a provável redução da eficiência do capital, garantindo, assim, a poupança compatível com os investimentos que asseguram a expansão da renda per capita.

\subsection{A DIVERSIFICAÇÃO DA INDÚSTRIA E A TENDÊNCIA À ESTAGNAÇÃO}

Note-se que a atratividade dos investimentos industriais é garantida pelo elevado preço dos bens finais da indústria e, em última análise, por elevação da taxa de câmbio e/ou por controles cambiais e restrições tarifárias às importações. A expansão da indústria requer três condições: mudança de preços relativos em favor de seu produto final, acesso a câmbio para expansão da capacidade produtiva, crescimento do mercado para seus produtos. A última condição é propiciada pelo processo de urbanização.

De modo geral, a expansão da renda faz com que a economia cresça à sombra de restrições cambiais, muitas vezes complementada por racionamento de divisas em favor das importações de bens intermediários e de capital não produzidos localmente. Já aos bens de consumo durável, igualmente importados, tem acesso apenas a parcela da 
população com altos rendimentos. Furtado (1966a) considera problemática a instalação de indústrias produtoras de equipamentos e de bens de consumo duráveis; ou melhor, questiona se o processo de substituição de importações pode levar à complementação da estrutura econômica e à diversificação do parque industrial, sem que daí decorram tensões e uma tendência à queda da taxa de crescimento econômico.

O ponto crítico é a elevada escala mínima eficiente da indústria moderna, típica do novo setor $\mathrm{P}_{5}$ (que engloba a indústria produtora de equipamentos e de bens duráveis). A escala mínima e o elevado custo dos investimentos colidem com as reduzidas dimensões do mercado, por sua vez condicionadas pela concentração de renda e pela incipiência do financiamento de vendas. Assim, a produção em $\mathrm{P}_{5}$ só se torna viável com preços finais muito elevados, o que não apenas afeta a formação de capital no restante da economia, inclusive agricultura moderna, mas também exerce um impacto negativo sobre a relação produto/capital. A rigor, o impacto negativo é duplo: encarecimento do capital e elevação da relação capital/produto "técnica", esta última uma decorrência típica da intensidade de capital da indústria mecânica moderna em face da restrição de mercado.

Na visão de Furtado (1966a), a elevação da taxa de poupança necessária para compensar tal mecanismo inibidor do crescimento econômico é de difícil obtenção - a taxa de lucro em $\mathrm{P}_{5}$ também cai, dada a operação abaixo da escala mínima eficiente -, daí advindo a tendência à estagnação.

Deve-se assinalar que, ao longo da análise, bem como ao introduzir a tendência à estagnação associada à instalação de $\mathrm{P}_{5}$, Furtado reitera sua visão geral da industrialização latino-americana, que tem como elemento angular os baixos salários resultantes da existência de um setor pré-capitalista significativo. A elevada relação capital/trabalho de $\mathrm{P}_{5}$ enfraquece o ritmo de transferência de população dos setores de subsistência para a indústria. Além disso, o próprio retardamento da transferência de trabalhadores agrícolas do setor de subsistência para a agricultura capitalista de mercado externo ou interno pressiona negativamente a relação produto/capital ${ }^{16}$.

Temos, assim, uma superposição de mudanças na estrutura de oferta, as quais provocarão: i) elevação da relação capital/trabalho agregada; ii) declínio da transferência de trabalhadores de setores de baixa para os de alta produtividade; iii) elevação da relação capital/produto global. Em suma, aumenta a concentração de renda em razão da oferta ilimitada de mão de obra e da elevação da relação capital/trabalho. A

\footnotetext{
${ }^{16}$ A agricultura primário-exportadora deixou de ser o núcleo do crescimento econômico. A demanda sobre os produtos da agricultura capitalista de mercado interno é prejudicada, conforme Furtado, pelo decréscimo do ritmo de subtração de mão de obra ao setor pré-capitalista.
} 
queda da taxa de crescimento, na visão de Furtado (1966a), seria estimulada pelo declínio da relação produto/capital "tecnológica”, ou inerente a $\mathrm{P}_{5}$ (em condições de mercado de massas restrito), e também pela perda de dinamismo da agricultura moderna, que reduz sua capacidade de absorção de mão de obra. A concentração de renda parece ser o elemento central do diagnóstico estagnacionista - razão pela qual, como foi dito acima, esse diagnóstico retém elementos centrais da lógica estruturalista, incluída a percepção das características do processo de desenvolvimento econômico com oferta ilimitada de mão de obra. No limite, a estagnação é um subproduto da moderna indústria, na qual a dotação de capital por trabalhador e a escala mínima eficiente são gigantescas. Na visão de Furtado (1966a), quando a industrialização perde sua capacidade de absorver a mão de obra do setor de subsistência, ela se torna problemática.

Sintomaticamente, a tese é reforçada por um contraste entre o caso geral, acima descrito, e o caso especial das economias que lograram eliminar o setor pré-capitalista ainda na fase primário-exportadora (Argentina é o arquétipo). Nesse último caso, preservada a renda do setor exportador por meio de políticas de compra de excedentes agrícolas e proteção cambial, subirão os preços relativos dos bens manufaturados, com estímulo à produção nativa. Em contraste com o caso geral, o setor manufatureiro terá de absorver mão de obra do setor exportador, já que inexiste setor pré-capitalista. Além disso, o setor exportador sofre uma queda da taxa de lucro em termos reais, em virtude da deterioração dos termos de troca. A mão de obra migrará para a indústria, cuja taxa de lucro aumentou.

O peso do ajuste recai sobre o setor exportador, o que, naturalmente, abre espaço para que o setor industrial utilize as divisas escassas. De todo modo, a expansão rápida da indústria substitutiva convive com subutilização de capacidade do setor exportador, o que acaba por representar um desafio adicional para toda a economia, às voltas com restrições na capacidade de importar e com alta nos preços dos equipamentos. $\mathrm{O}$ resultado será aqueda da produtividade média da economia. Furtado (1966a) conclui que economias como a Argentina, cujas condições naturais asseguravam elevada produtividade dos fatores, não conseguem mais traduzir essa vantagem específica em elevadas taxas de crescimento. A única forma de contornar a queda de produtividade seria uma escalada tecnológica, tanto na agricultura quanto na indústria, mas há ceticismo em relação a essa possibilidade, inclusive porque a redução da taxa de lucro dificulta a readequação tecnológica - única forma de conviver virtuosamente com salários em alta.

No Brasil, em contraste, os salários não se viram elevados pela expansão da manufatura. Não havendo pressão salarial, a industrialização por substituição de importações não representou obstáculo à retomada das exportações primárias quando as con- 
dições do mercado internacional se mostraram favoráveis ${ }^{17}$. Trata-se, paradoxalmente, do êxito perverso (embora temporário e problemático) do modelo concentrador.

Aliás, vale observar que nas passagens do terceiro capítulo que sucedem o aludido contraste entre o caso geral e o particular, o quadro brasileiro se imporá como uma individualidade do caso geral. Exemplo acabado de país com excedente estrutural de mão de obra, o Brasil também tem maior extensão de mercado, graças ao tamanho da população e à crescente urbanização. Nessas condições, Furtado (1966a) concede que as possibilidades de êxito da instalação dos setores industriais agrupados em $\mathrm{P}_{5}$ são maiores. A atenção especial concedida ao caso brasileiro é importante para nuançar a tese estagnacionista, como veremos.

De todo modo, voltando ao caso geral, as características do mercado de trabalho e as restrições cambiais implicam aumento da concentração de renda e elevação dos preços dos equipamentos. $\mathrm{O}$ encarecimento dos equipamentos significa mais investimento por unidade de produto - o que representa um efeito inverso ao das inovações tecnológicas que poupam capital. Essa observação é importante porque, em geral, poupança de capital representa uma característica do processo de inovação tecnológica. Furtado (1966a) prossegue dizendo que assim como tecnologias poupadoras de capital, em face de salários estáveis, elevam a taxa de lucro ou produzem uma baixa no preço do produto, o contrário ocorreria no caso geral latino-americano por uma razão peculiar: com salários determinados exogenamente, a elevação da taxa de lucro se realiza no conjunto do sistema econômico, e não na indústria que inovou. A concentração de renda é inevitável - e vale lembrar que, em certa medida, isso contrarresta os efeitos da baixa eficiência do capital sobre o crescimento econômico. O resultado final é concentração de renda e poupança ascendentes em face do declínio da absorção de mão de obra do setor pré-capitalista.

A despeito disso, onde os mercados forem de maiores dimensões (Brasil), "é perfeitamente concebível que as indústrias de bens de capital superem as dificuldades da primeira fase e venham a beneficiar-se de certas economias de escala, detendo a tendência [...] de encarecimento relativo dos equipamentos" (Furtado, 1966a, p. 85). O êxito no processo substitutivo, nessas condições, terá como contrapartida o aguçamento das tensões sociais. A tendência à estagnação seria, nesse caso, menos "técnica” do que "política", ou o produto de tensões que, "alcançando um ponto crítico, teriam que afetar adversamente o processo de crescimento" (Furtado, 1966a, p. 85). Enfim, o Brasil parece a Furtado um caso de tendência à estagnação "política", ou seja, aquela na qual as possibilidades de desenvolvimento econômico são afetadas pelo acúmulo de tensões sociais.

\footnotetext{
17 Furtado se refere à retomada das exportações de café brasileiras nos anos 1950.
} 
Para concluir, de modo surpreendente Furtado (1966a) introduz no modelo as mudanças tecnológicas. Até aqui, de acordo com o autor, ficamos restritos aos efeitos decorrentes de alterações na composição da demanda, provocadas pela crise mundial e políticas protecionistas decorrentes. As únicas alterações nas funções de produção explicam-se por "fatores exógenos ao processo econômico", ou seja, os decorrentes do fato de os equipamentos importados serem portadores de inovação tecnológica. Agora, indaga-se se novas técnicas não virão a anular a ação dos fatores que tendem a produzir a concentração de renda.

A resposta baseia-se em uma segmentação entre agricultura e indústria, ou setores menos e mais usuários de novos equipamentos importados. Dentre as indústrias, as produtoras de bens duráveis e de equipamentos são as mais afetadas pelos novos equipamentos. De acordo com Furtado (1966), se admitirmos que o progresso tecnológico é neutro, diante de salários estáveis ambos os tipos de aumento de produtividade - do capital e da mão de obra - reduzem a participação dos salários no total da renda. A possibilidade de a queda do preço dos bens manufaturados exercer um alargamento da cesta de subsistência e, por essa via, uma elevação dos salários, é uma concessão aventada, porém descartada por seu efeito ser estimado como irrelevante em função da pequena penetração dos bens manufaturados na cesta de consumo do setor pré-capitalista. Em qualquer circunstância, os salários dos trabalhadores teriam um ganho inferior àqueles obtidos pelos consumidores mais intensivos de produtos manufaturados - sabe-se que Furtado associava o consumo de duráveis a reduzidos contingentes de altas rendas. Em consequência, a tendência concentradora é incontornável, mesmo admitindo-se elevação na produtividade média. E, de todo modo, o "coeficiente de capital crescente" reduz a eficiência econômica do investimento de modo geral, reforçando a tendência à estagnação.

\section{O AMBIENTE TEÓRICO DO MODELO DE ESTAGNAÇÃO E SUAS ORIGENS}

Tomando-se como ponto de referência Formação Econômica do Brasil, não se pode deixar de reconhecer que as obras de meados dos anos 1960 - Subdesenvolvimento e Estagnação na América Latina e Teoria e Política do Desenvolvimento Econômico, particularmente - refletem a incorporação de novas referências teóricas ao modelo histórico-estrutural de Furtado.

Parte dessas referências já era familiar ao autor desde sua temporada de 1957 a 1958 em Cambridge. Furtado (1985) revela que, na ocasião, participou dos extensos debates acerca dos modelos de crescimento dos anos 1950, em particular do modelo de Kaldor de 1957. Curiosamente, a obra redigida na ocasião - Formação Econômica 
do Brasil - não revela traços das teorias pós-keynesianas de crescimento. Já Desenvolvimento e Subdesenvolvimento (publicada em 1961) faz referências aos modelos de crescimento, enquanto Teoria e Política do Desenvolvimento Econômico, uma extensão da obra anterior,tem um capítulo dedicado à descrição dos "modelos dinâmicos" (Harrod, Solow, Meade, Kaldor). Sem o propósito de revisar os "modelos dinâmicos", Subdesenvolvimento e Estagnação retém os traços da equação de equilíbrio dinâmico de Harrod e de Domar, a qual, a partir da identidade entre poupança e investimento, subordina a taxa de crescimento ao produto entre taxa de investimento e relação produto/capital.

Acrescente-se que, na temporada norte-americana de 1964-1965, Furtado atualizara-se em política internacional moderna, além de ter incorporado as grandes empresas internacionais a sua visão do subdesenvolvimento. Como mencionado, autores como Kennan e Morgenthau deram o pano de fundo à revisão da política internacional no período de Guerra Fria, tratada nas discussões sobre os "obstáculos externos ao desenvolvimento". Já a visão de Hymer sobre a empresa multinacional e sua expansão à escala internacional preencheu uma lacuna de trabalhos anteriores, fazendo com que as empresas internacionais, com suas características, escolhas tecnológicas e modos de atuação, fossem incorporadas ao processo de reconstrução racional da história de Furtado.

Enfim, os trabalhos de Furtado de meados dos anos 1960 são mais "internacionalizados", no sentido de incorporarem uma visão atualizada do mundo desenvolvido (política e empresas multinacionais) e revelarem familiaridade com importantes aspectos da teoria econômica dos anos 1950 e início dos anos 1960. Note-se, no entanto, que a combinação de multiplicador e acelerador antecede os trabalhos da segunda metade dos anos 1960. Na verdade, tratava-se de um recurso absorvido pela prática de planejamento econômico da CEPAL, em particular nos exercícios de estimativa da taxa máxima ou potencial de crescimento dos diversos países da América Latina ${ }^{18}$.

O trabalho Perspectivas da Economia Brasileira (Furtado, 1958) é possivelmente aquele no qual a metodologia de estimativa do potencial de crescimento aparece de modo mais sugestivo ${ }^{19}$. Nesse pequeno livro, fruto de uma transcrição de conferências realizadas no "Curso de Treinamento em Problemas de Desenvolvimento Econômico", promovido em 1957 pela CEPAL no Rio de Janeiro, Furtado estima o potencial de crescimento das economias por meio da combinação de propensão a poupar e relação produto/capital. Especificamente, afirma que o ritmo de crescimento depende do "esforço de poupança" e da relação produto/capital. Enquanto o primeiro limita a taxa

\footnotetext{
18 Ver CEPAL (2000), em particular o capítulo III, que foi elaborado por Furtado em 1955.

19 Esse texto de pequena divulgação veio a ser reeditado apenas em 2012.
} 
possível de investimento, a segunda define a "eficiência do capital". Com base em dados levantados pelo grupo CEPAL-BNDE, Furtado (1958) estima que o Brasil pode alcançar uma taxa de crescimento anual da ordem de $7 \%$ a $8 \%$, tendo a produção real entre 1945 e 1954 ficado aquém desse potencial em razão de desequilíbrios diversos, dentre os quais a escassez de divisas e a decorrente subutilização da capacidade produtiva. Trata-se de evitar a subutilização da capacidade produtiva, dirigindo a capacidade de importação aos setores em condições de investir, ou eliminando gargalos básicos em infraestrutura. Estamos no terreno da subutilização da capacidade instalada, vale dizer, em uma situação em que desequilíbrios localizados prejudicam a utilização ótima dos equipamentos.

Furtado (1958) acrescenta que a estimativa BNDE-CEPAL, baseada em hipóteses sobre o movimento de capitais a longo prazo, é de que o crescimento no quinquênio subsequente a 1957 seria inferior ao observado no período 1939-1953. A neutralização dessa tendência à desaceleração exigiria o aumento da produtividade média do capital, intensificação das exportações, programas governamentais em transportes e energia e, afinal, melhorias na educação. O propósito é elevar a relação produto/capital média. Vê-se que a produtividade do capital é considerada um elemento suscetível a mudança deliberada. A taxa de poupança, ao contrário, é vista como relativamente estável e fortemente condicionada pela concentração de renda e pela propensão das classes de rendas altas a emular o padrão de consumo dos países desenvolvidos. Nesse terreno, a intervenção cabível consistiria em políticas fiscais especificamente voltadas à elevaçãoda taxa de poupança.

Desenvolvimento e Subdesenvolvimento (Furtado, 1961) volta ao tema, com a simulação dos efeitos do investimento sobre o produto líquido, dada uma produtividade média do capital de 0,5. Nele, Furtado discute também o desemprego estrutural de fatores nos países subdesenvolvidos e a impossibilidade de adaptar a tecnologia às dotações internas de fatores, além dos condicionamentos "sociológicos" dos padrões de consumo, que inibem a taxa de investimento. E, finalmente, considera variações do grau de utilização da capacidade produtiva provocadas por gargalos em infraestrutura.

Simulações semelhantes são retomadas em Teoria e Política do Desenvolvimento Econômico (Furtado, 1967). Nessa obra, o tratamento dado ao acelerador é mais lato, exatamente por abranger uma revisão dos modelos de crescimento dinâmico do pós-guerra. Harrod e Domar, pondera Furtado (1967), acrescentaram à análise keynesiana clássica do multiplicador o efeito das inversões sobre a capacidade produtiva, tornando o estoque de capital uma variável da equação do equilíbrio dinâmico.

Em outra - e sugestiva - passagem, é feita menção sumária aos diversos modelos de crescimento econômico e derivadas as condições de equilíbrio de pleno emprego. Furtado (1967) volta aos exercícios de planejamento para os países latino-americanos, 
destacando a possibilidade de variação do produto per capita em curto prazo em função das flutuações do grau de utilização da capacidade produtiva. Trata-se da situação em que o numerador da relação produto/capital oscila, admitindo-se a capacidade produtiva como dada - a clássica situação em que pode ocorrer uma aceleração da atividade econômica no momento posterior a uma súbita desaceleração, sem necessidade de expansão da capacidade produtiva.

Teoria e Política do Desenvolvimento Econômico destaca ainda as possibilidades de alteração da taxa de capitalização das economias, relacionada à relação entre poupança (e investimento) e consumo, simulando resultados para valores diversos da taxa de poupança e do acelerador. Acresça-se que a tendência à estagnação recebe um tratamento especial, no capítulo 19, no qual Furtado (1967) se refere à redução da eficácia dos investimentos ao se passar à produção local dos produtos de "difícil substituição". Trata-se de uma menção genérica, que abrange os obstáculos à formação de poupança e ao investimento. De todo modo, as restrições do lado da oferta recebem tratamento especial, com destaque para a tendência à elevação da relação capital/trabalho, especialmente na produção de bens duráveis. Furtado (1967) sugere que se atue sobre as exportações e que a política fiscal complemente a poupança. Enfim, reconhecendo a força das variáveis capazes de produzir estagnação, não chega propriamente a formular um modelo de estagnação.

Em Análise do Modelo Brasileiro (Furtado, 1972), obra em que Furtado procura explicar as razões de sucesso da economia brasileira após 1967, os componentes básicos do enfoque estagnacionista não desaparecem de todo. Especificamente discutem-se as possibilidades de sustentação de altas taxas de crescimento em uma economia que tem como uma de suas características a elevada concentração de renda. Ao reafirmar que a taxa de crescimento está relacionada à aptidão para gerar poupança e à produtividade média dos investimentos, Furtado (1972) considera 6\% ao ano uma taxa de crescimento que traduz as "relações estruturais básicas" da economia brasileira, ou uma taxa cuja obtenção não encontra obstáculos pelo lado da oferta. Pondera, no entanto, que no início dos anos 1960 ocorrera uma redução brusca da relação produto/capital, a despeito de não se haver reduzido dramaticamente a taxa de poupança. A conclusão é de que o sistema subutiliza a capacidade produtiva por ser incapaz de garantir automaticamente o perfil de demanda requerido para a sustentação do crescimento - o que concentra as atenções no perfil da demanda. Sem nos estendermos às particularidades de Análise do Modelo, basta apontar a relativa centralidade da relação produto/capital na explicação das flutuações econômicas e das possibilidades de êxito do modelo concentrador. Em síntese, a utilização do acelerador e/ou o reconhecimento dos fatores estagnacionistas se estende por obras diversas e por um longo período. 
Em Perspectivas da Economia Brasileira e Desenvolvimento e Subdesenvolvimento, a relação capital/produto integra exercícios de cálculo da taxa possível de crescimento (dada a propensão a consumir). Em Teoria e Política do Desenvolvimento Econômico, a interação entre multiplicador e acelerador é admitida como parte central da discussão pós-keynesiana e, ato contínuo, integrada a exercícios aplicados às economias subdesenvolvidas. Finalmente, em Subdesenvolvimento e Estagnação, a relação capital-produto converte-se não apenas em parte essencial dos modelos descritivos das diversas fases por que passam as economias latino-americanas (do modelo primário-exportador à diversificação industrial), mas também em elemento explicativo da tendência à estagnação: as modernas indústrias utilizam tecnologias que requerem mercado de massas, e as pequenas dimensões dos mercados para bens duráveis e de investimento nos países subdesenvolvidos levam a uma subutilização da capacidade produtiva. A tendência à estagnação é justamente o resultado da convivência conflituosa de dualismo estrutural (e a tendência à contenção salarial a ele associada) e modernas tecnologias.

\section{CONCLUSÕES}

Como foi visto, em Formação Econômica do Brasil Furtado (1959) utiliza a variação do grau de utilização da capacidade da indústria como um fator na explicação do crescimento econômico em um contexto bem determinado, qual seja, o de superação da brusca contração econômica causada pela queda das exportações na Grande Depressão. Em condições de proteção cambial e de elevação dos preços relativos de seus produtos, a indústria voltada ao mercado interno logrou ocupar a capacidade já existente, elevando a rentabilidade do capital sem necessidade de novos investimentos. Essa manobra defensiva favoreceu a recuperação do nível de atividades e promoveu uma translação dos setores dinâmicos, da agricultura de exportação para a indústria de bens de consumo não duráveis. Note-se, no entanto, que i) trata-se de analisar uma fase do ciclo apenas, e uma fase na qual a taxa de investimento da indústria é baixa; ii) a relação produto/capital não é incorporada ao núcleo da análise econômica, a qual continua a se reportar ao multiplicador keynesiano ou a uma combinação de multiplicador e restrições cambiais.

A relação produto/capital penetra nos modelos de Furtado em outros trabalhos, anteriores e posteriores a Formação Econômica, em duas situações distintas. Por um lado, a "eficiência do investimento", em conjunto com a propensão a poupar, passa a ser a base das estimativas da taxa potencial e efetiva de crescimento econômico dos países latino-americanos. Temos aqui um eco das equações de equilíbrio dinâmico de Harrod e de Domar, no contexto bem específico de simulação do potencial de cresci- 
mento. Nesse ambiente, Furtado tende a considerar a relação produto/capital um elemento estrutural, afetado por condições tecnológicas de lenta mudança, como é do espírito do modelo de Harrod. No entanto, assinala as variações da relação produto/ capital nos momentos de recuperação cíclica de uma crise e de contração da capacidade de importação. Nessa última situação, pode sobrevir perda de eficiência, provocada por mudanças drásticas de preços relativos, rompimento de nexos interindustriais e desabastecimento localizado. Furtado está atento à necessidade de evitar os gargalos de infraestrutura, que reduzem a eficiência dos fatores e, por definição, elevam a relação capital/produto. Perspectivas da Economia Brasileira faz ainda menção a variáveis não tecnológicas capazes de alterar a eficiência econômica, como a educação.

Já na análise específica da crise das economias latino-americanas da década dos 1960, as variações da relação produto/capital assumem o papel de elemento ativo dos modelos. A impressão que se tem é a de que a taxa de poupança passa a ser considerada um elemento razoavelmente estável, enquanto a eficiência do capital oscila. Para Furtado (1966a), inequivocamente, a crise econômica associada a etapas mais avançadas do processo de substituição de exportações é induzida por oscilações da relação produto/capital. Como foi visto, a expansão da indústria de bens de consumo durável e de bens de capital, que opera com escala mínima eficiente elevada, pode ser posta em xeque pela estreiteza dos mercados consumidores. A combinação entre escala mínima eficiente elevada e mercado restrito implica relação produto/capital baixa, o que provoca queda da eficiência do capital e ameaças à rentabilidade.

Ora, a utilização da relação produto/capital nesse específico contexto - o de diversificação e complementação da estrutura produtiva dos países subdesenvolvidos - envolve ao menos dois novos - e problemáticos - elementos. O primeiro foi mencionado acima: de elemento estrutural, a relação produto/capital passa a ser considerada uma variável atuante na definição das variações do ritmo de crescimento econômico. Isso vale tanto para o curto prazo - oscilações provocadas por mudanças na situação cambial - quanto para o longo prazo, como tendência das economias latino-americanas, à medida que o processo de substituição de importações avança.

O segundo elemento é a aplicação da relação produto/capital a setores econômicos diversos; vale dizer, as variedades de relação produto/capital passam a ser o elemento distintivo dos modelos de Furtado, em especial em Subdesenvolvimento e Estagnação. Temos agora uma relação para a agricultura de exportação (a rigor, duas, se considerarmos capital associado ou não a poupança prévia), outra para a indústria tradicional e outra para a indústria de bens duráveis ede equipamentos. A trajetória da economia latino-americana, da dominância da agricultura de exportação para a da indústria diversificada, representaria a trajetória de uma relação produto/capital naturalmente elevada para outra tendencialmente cadente. A questão essencial passa a ser a possibi- 
lidade de compensação da tendência à queda da produtividade do capital global por meio da elevação da taxa de poupança e de investimento.

Tenho a impressão de que esse desdobramento setorial da relação produto/capital é uma novidade ousada tanto em relação aos modelos de crescimento tradicionais, quanto aos exercícios de estimativa de potencial de crescimento utilizados nos cursos da CEPAL. Por outro lado, e como procurei argumentar na seção 3, o desdobramento é funcional à reconstrução racional da história de Furtado, ao menos no que se refere aos seguintes aspectos: captação das especificidades da economia agroexportadora, em particular as da economia do café; e fornecimento de uma espécie de rationale econômica para a superação da crise da economia agroexportadora (a ocupação de capacidade ociosa eleva a relação produto/capital e, em decorrência, a rentabilidade de capital, estimulando o investimento). Em especial, Furtado (1966a) consegue dar resposta nos dois casos - agricultura de exportação e lançamento da substituição de importações - a seu dilema analítico permanente: como garantir a poupança requerida pelos investimentos necessários à sustentação de uma taxa de crescimento elevada.

No modelo com dominância de agricultura exportadora, a poupança é garantida "naturalmente" pela formação de capital no interior do próprio setor agroexportador, havendo identidade entre o produto do setor e investimento. No caso da industrialização sob liderança de indústrias tradicionais, a mera hipótese de elevação da rentabilidade em condições de salários limitados conduz a um aumento da concentração de renda, o que assegura os lucros e a poupança requeridos pela expansão dos investimentos industriais. Em suma, nesses dois casos Furtado (1966a),de certo modo, complementa seu modelo clássico pela adição da relação produto/capital, feita a ressalva de que a elevação da eficiência do capital na indústria tradicional é um fenômeno transitório, associado apenas à fase de ocupação de capacidade ociosa.

Quando os investimentos se tornam necessários, existe a possibilidade de que a relação produto/capital global decresça em relação à situação anterior da indústria e, certamente, em relação àquela que caracteriza a agricultura de exportação. Nessa situação, apenas a hipótese de aumento da taxa de poupança e de investimento, em função das margens de lucro acrescidas pelo aumento da produtividade do trabalho em condições de salários limitados, pode explicar a sustentação e/ou elevação da taxa de crescimento econômico. Estamos no domínio da condição harrodiana de equilíbrio, mas cabe assinalar que há uma lacuna no tratamento dos preços relativos, uma vez que a mesma taxa de câmbio que impulsiona o preço relativo do produto da indústria eleva o custo do investimento. Em resumo, os impactos sobre a relação produto/capital provêm tanto do numerador quanto do denominador e, a rigor, a transição em direção a um modelo de crescimento "para dentro" requer hipóteses ad hoc sobre política cambial, proteção a setores da indústria específicos, subsídio ao investimento etc. 
Já a diversificação da indústria leva a explicação de Furtado (1966a) a um dilema. O pano de fundo é a interveniência de economias de escala, típicas da indústria moderna, em condições de mercado interno restrito. O êxito dessas indústrias dependerá de proteção cambial e de uma estrutura de preços relativos que garanta sua rentabilidade, mesmo em condições de subutilização da capacidade instalada e de custo de investimento elevado. Enfim, a viabilidade da indústria de equipamentos eleva o custo do capital para todos os setores de atividade econômica, inclusive agricultura moderna. Impossível prever o que ocorrerá com a relação produto/capital, simplesmente porque os preços relativos de muitos bens são afetados pela variação cambial, pela elevação dos custos do investimento, pela sensibilidade dos diversos setores à proteção cambial e aos aumentos de preços.

O modelo simplificado de preços relativos, que leva em consideração apenas a taxa de câmbio, não é mais suficiente para explicara diversidade de situações observadas em cada setor de atividade econômica. Penso que estruturas econômicas complexas tornam o método de Furtado no mínimo impreciso, pela simples razão de não podermos assegurar, à margem de uma análise detalhada dos preços relativos, a tendência da relação produto/capital setor a setor. Ou seja, nos termos do modelo, sequer podemos afirmar que a relação produto/capital tende ao declínio.

No entanto, cabe lembrar que, para as economias que lograram diversificar seu parque industrial - como a do Brasil -, a queda da taxa de crescimento decorreria dos impasses políticos resultantes da impossibilidade de incorporar a população aos setores modernos e/ou com relações de trabalho formalizadas, para não falarmos em impossibilidade de esgotar o excedente de mão de obra e desconcentrar a renda. Para Furtado (1966a), os dilemas políticos produzidos pelo modelo econômico levariam a economia e a política a um impasse.

\section{REFERÊNCIAS}

ADELMAN, J. Wordly Philosopher: the odyssey of Albert O. Hirschman. Princeton: Princeton University Press, 2013.

BIANCONI, R. Estagnação latino-americana e estratégia brasileira de desenvolvimento: análises do início do exílio de Celso Furtado. In: CONGRESSO BRASILEIRO DE HISTÓRIA ECONÔMICA, 11., 2015, Vitória, ES, 14-16 set.

BOIANOVSKY, M. A formação política do Brasil segundo Furtado. Revista de Economia Política, v. 34, n. 2, 2014.

BUGELLI, A. H.; PIRES, J. M. Uma revisão da teoria da estagnação de Celso Furtado e a crise econômica dos anos 1960. Cadernos do Desenvolvimento, ano 6, n. 9, 2011.

CEPAL. "Introdução à Técnica de Planejamento". In: BIELSCHOWSKY, R. Cinquenta anos de pensamento na CEPAL. Rio de Janeiro: Record, 2000. 
CEPÊDA, V. A. “O pensamento político de Celso Furtado: desenvolvimento e democracia”. In: BRESSER-PEREIRA, L. C.; REGO, J. M. (Orgs.). A Grande Esperança em Celso Furtado. São Paulo: Editora 34, 2001.

FURTADO, C. Perspectivas da Economia Brasileira. Rio de Janeiro: MEC, 1958.

FURTADO, C. Formação Econômica do Brasil. Rio de Janeiro: Fundo de Cultura, 1959.

FURTADO, C. Desenvolvimento e Subdesenvolvimento. Rio de Janeiro: Fundo de Cultura, 1961.

FURTADO, C. Political obstacles to economic growth in Brazil. International Affairs, London, v. 41, 1965a.

FURTADO, C. Development and Stagnation in Latin America: a structuralist approach. Studies in Comparative International Development, Yale, vol. 1, n. 11, 1965b.

FURTADO, C. Subdesenvolvimento e Estagnação na América Latina. Rio de Janeiro: Civilização Brasileira, 1966a.

FURTADO, C. Développement et stagnation en Amérique Latina: une aproche structuraliste. Annales Économies, Societés, Civilisations. 2e anée, n. 1, 1966b.

FURTADO, C. Desarrollo y estancamento en America Latina (Enfoque estructuralista). Desarrollo Económico, v. 6, n. 22/23, jul./dec. 1966c.

FURTADO, C. Teoria e Política do Desenvolvimento Econômico. São Paulo: Companhia Editora Nacional, 1967.

FURTADO, C. Análise do Modelo Brasileiro. São Paulo: Civilização Brasileira, 1972.

FURTADO, C. A Fantasia Organizada. São Paulo: Paz e Terra, 1985.

FURTADO, C. A Fantasia Desfeita. São Paulo: Paz e Terra, 1989.

FURTADO, C. Os Ares do Mundo. São Paulo: Paz e Terra, 1991.

FURTADO, C. Formação Econômica do Brasil. São Paulo: Companhia das Letras, 2009.

FURTADO, C.; MANESCHI, A. Um modelo simulado de desenvolvimento e estagnaçao na América Latina. Revista Brasileira de Economia, Rio de Janeiro, FGV, v. 22, n. 2, 1968.

LEWIS, W. A. “O desenvolvimento econômico com oferta ilimitada de mão de obra”. In: AGARWALA, A. N.; SINGH, S. P. A Economia do Subdesenvolvimento. Rio de Janeiro: Contraponto, 2010.

NURKSE, R. Problems of capital formation in underdeveloped countries. Oxford: Basil Blackwell, 1953.

OLIVEIRA, F. Un clássico de El Trimestre Económico: Celso Furtado y el paradigma del subdesarrollo. El Trimestre Económico, México, v. 50, n. 198(2), 1983.

RODRIGUEZ, O. O Estruturalismo Latino-Americano. Rio de Janeiro: Civilização Brasileira, 2009.

SALM, C. "O debate sobre a tendência à estagnação". In: MALTA, M. (Org.). Ecos do Desenvolvimento: uma história do pensamento econômico brasileiro. Rio de Janeiro: IPEA/Centro Celso Furtado, 2011.

TAVARES, M. C.; SERRA, J. Más allá del estancamento: una discusión sobre el estilo de desarrollo reciente. El Trimestre Económico,México, v. 38, n. 152(4), p. 905-950, 1971. 